\title{
Cómo se cuentan los viajes: estrategias narrativas en Sergio Chejfec y Martín Caparrós
}

\author{
Juliana González-Rivera ${ }^{1}$
}

Resumen. Sergio Chejfec y Martín Caparrós, autores hispanoamericanos, residentes fuera de su país de origen y que han tratado poéticas del movimiento, sirven como punto de partida para analizar las estrategias narrativas del viajero contemporáneo. Cómo se cuentan los viajes, qué elementos reúnen o separan estos dos autores, qué nos dice su escritura que permite identificar su condición con la de viajeros y sus libros con la escritura de viajes -ese género fronterizo, híbrido, mestizo-. Entre los elementos analizados está la búsqueda, la hipertextualidad, el problema del tiempo y el espacio, la condición de testigo y traductor del viajero y la premisa informativa que forma parte del relato de viaje más allá de las estrategias narrativas.

Palabras clave: literatura de viajes; Martín Caparrós; Sergio Chejfec; escritores viajeros; poéticas de viaje.

[en] How travels are written: narrative strategies in Sergio Chejfec and Martín Caparrós

Abstract. Sergio Chejfec and Martin Caparrós, Hispano-American writers who have addressed different travel poetics, serve as a starting point for analyzing the narrative strategies of contemporary traveler writers: how their travels are written and which elements distinguish both author's writing, their traveler's condition and their writing as travel literature. Among the elements analyzed there are: traveler's seeking, hypertextuality, the problem of time and space and the traveler as witnesses and translator.

Keywords: Travel Writing; Martín Caparrós; Sergio Chejfec; Travel Writers; Travel Poetics.

Sumario. 1. La búsqueda. 2. Teatralidad y cartografía. 3. ¿Viajeros? Hiperviaje, metaviaje, interviaje. 4. Técnicas y estrategias narrativas de un género híbrido. 5. La duda: la impotencia comunicativa.

Cómo citar: González-Rivera, J. (2018) Cómo se cuentan los viajes: estrategias narrativas en Sergio Chejfec y Martín Caparrós, en Anales de Literatura Hispanoamericana 47, 219-238.

\section{La búsqueda}

"Si es por buscar, mejor que busques lo que nunca perdiste”, solía decirle su padre a Martín Caparrós (2011: 6). Pero “buscar, el qué” se pregunta el escritor. Todo

1 Universidad EAFIT, Medellín. Colombia.

E-mail: juligonza26@hotmail.com 
viaje comienza con una pregunta, una abstracción, esa entelequia que le dice al viajero que en algún lugar -que por lo general supone lejos del suyo- existe una respuesta. El problema es que la pregunta nunca es clara y ello implica un esfuerzo de la imaginación. Es ahí donde comienzan los viajes: antes que en el camino, en la cabeza de sus protagonistas. En muchos casos se trata de la curiosidad, esa cualidad que Ortega y Gasset definió como la plena vitalidad del espíritu y que los griegos entendían como un síntoma de la juventud, esa que hace que el hombre se inquiete por lo que hay «más allá» o por el deseo de cruzar la frontera -esa expresión que definió, por ejemplo, la vida de Ryszard Kapuściński (2006: 86)-. Para otros, el viaje empieza en una huida, la llamada de la aventura, la caza de una recompensa o el deseo de instrucción. La búsqueda implica carencia y el movimiento es una manera de intentar solventarla.

Pero buscar, solventar el qué: "me contentaría con saber qué estoy buscando. Quizá en el camino lo consiga”, escribe Caparrós en El interior (ibíd.: 6). Y en Una luna: "Viajar es, por supuesto, la confesión de una impotencia: ir a buscar lo que te falta en otros lugares" (Caparrós 2009: 16). También Sergio Chejfec alude a la búsqueda en Mis dos mundos cuando asegura que persigue cosas que no encuentra, que no existen o no aparecen, por lo que sus caminatas son ceremonias tortuosas que ya no le satisfacen y aún así mantiene ese deseo imperioso y contradictorio por el que no puede evitar lanzarse a caminar por las calles (Chejfec 2008: 22).

Ese es el punto de partida, la excusa para viajar, la búsqueda. "Se supone que viajar es lo que me gusta, que es una suerte hacerlo", dice Caparrós (2009: 9). Pero duda, se cuestiona el propósito: "¿Cuándo fue que decidimos que había que hacer las cosas con un objeto y objetivo?” (ibíd.). Chejfec, de "curiosidad endeble” (Chejfec 2008: 9), alude a una especie de enfermedad en las piernas: el don del desplazamiento, el vagabundeo como adicción, ruina y salvación (ibíd.: 14), al tic físico y social de la caminata (íbid.: 17), pero define la suya como una escritura inútil, improductiva y bastante banal (ibíd.: 118).

Viajar, entonces, para qué. En Más allá del bien y el mal Nietzsche se preguntaba: “Caminante, ¿quién eres tú? [...] ¿Qué has ido a buscar?” (2003: 258). El alemán asumía que viajero es el que busca. Quizá porque la primera aproximación al hombre que se desplaza es necesariamente teórica, abstracta. Viajar suele estar asociado a la actitud del filósofo: De «la Caverna»-desde el mundo sensible de las sombras hacia el inteligible de las Ideas-, surge una de las grandes alegorías de la búsqueda del conocimiento. El viaje es metáfora de la idea. De ahí que las primeras preguntas -de dónde venimos, a dónde vamos después de la muerte, el origen del universo, el sentido de la vida y la cuestión del tiempo y el espacio- entronquen desde la antigüedad hasta hoy con ese personaje que se mueve para buscar respuestas. Porque como dijo Montaigne, no hay para el hombre "ningún deseo más natural que el deseo de conocimiento. Probamos todos los medios que nos pueden llevar hasta él" (Montaigne: libro XIII, 1589). Y uno de esos medios es el viaje: "el viajero convierte su periplo en una experiencia filosófica en tanto la conquista es mucho más que el hallazgo de un paraje indómito y la anécdota se convierte en un objeto filosófico de interés” (Castro 2008: 2). Parece que las respuestas están allá, afuera, lejos.

Martín Caparrós y Sergio Chejfec encajan en esa búsqueda. Se trata del deseo de comprender. Irse es dejar la caverna, dice Caparrós (2010: 159) y se define 
como "alguien ansioso de saber" (ibíd.: 139). Se trata de un conocimiento exterior (el mundo y sus problemáticas), y un conocimiento interior que tiene que ver con su propio viaje vital y su lugar en el mundo. Ambos autores abordan cuestiones filosóficas como la metafísica del espacio, el problema del tiempo. Caparrós viaja "para cambiar el tiempo", porque viajar es la mejor manera que conoce de derrotar el reloj (ibíd.: 134). Una derrota breve pero que consigue que el tiempo sea menos veloz, se estile, sea elástico, momentos que, aunque efímeros, cuentan (Caparrós 2009: 77)-. En su escritura importa el tiempo atmosférico, el metafísico, los tiempos verbales. Y luego están sus viajes en el tiempo, como en Larga Distancia -donde incluye perfiles de personajes del pasado-. Y viaja para "tratar de captar el movimiento. No entenderlo, no descomponerlo: registrarlo sin que se deshaga" (Caparrós 2010: 27). El tiempo es su elemento a vencer. En Chejfec, sin embargo, no importa el tiempo ni el espacio porque el recorrido es el de las ideas que se bifurcan, no el de los pasos. Su territorio es lingüístico. Su tiempo, sintáctico. De ahí que sus libros no se dividan en capítulos: su esquema es de planos narrativos que se superponen, capas, una cadena de pensamiento. Su espacio es mental, casi se podría prescindir de la dimensión física. Pero al mismo tiempo es un juego espacial:

Con el tiempo se pueden hacer muchas cosas. Tenemos diferentes herramientas para medir el tiempo empírico y podemos también examinarlo de un modo metafísico. Sin embargo, el espacio está siempre sometido únicamente a dimensiones empíricas. El tiempo vale para todo, en literatura y en otras artes. Puedes jugar mucho con el tiempo... En cambio, el espacio es más etéreo, más discontinuo y amorfo. Me interesa poner en primer plano esa relación difusa y ambigua que pueden tener los personajes o el narrador con la dimensión espacial [...] Durante un tiempo yo solía decir que quería tratar el espacio como si fuese tiempo. Darle al espacio una dimensión sucesiva. Seguramente algo condenado al fracaso... pero es que la literatura no tiene por qué representar el éxito (Trejo 2009: 15).

Pero no se trata solo de cuestiones metafísicas: Caparrós viaja para entender el mundo contemporáneo: enviado por el Fondo de Población de Naciones Unidas, aborda grandes temas como la inmigración, la pedofilia, el hambre. En Larga Distancia y La Guerra moderna, nos cuenta el mundo, en Dios mío, un retrato de la India, Una luna contiene historias de inmigrantes y en Contra el cambio realiza un hiperviaje por las supuestas causas y consecuencias del cambio climático. Sergio Chejfec puede escribir sobre una artista como excusa para retratar un país o relatar el paseo por un parque para reflexionar sobre el tiempo vivido. Pero en ambos se trata, sobre todo, de un proyecto literario: escribir para viajar, viajar para escribir.

Por eso aunque Baudelaire definiera como verdaderos "solo los viajeros que parten por partir" en el famoso verso de Las flores del mal (Baudelaire 2007: 249), no existe viaje sin propósito: incluso el vagabundeo del flâneur o las vacaciones del turista tienen objetivos implícitos de contemplación, descanso, peregrinación o placer en lo desconocido. E incluso los escritores románticos que establecieron como seña de identidad "el viaje por el viaje”, también tenían su recompensa en el 
placer estético y en la escritura que, como dice Michel Butor, era el objetivo principal de los viajeros del Romanticismo (Butor 1972: 12).

\section{Teatralidad y cartografía}

Para Martín Caparrós y Sergio Chejfec el desplazamiento es, sobre todo, el pretexto literario, contexto de su escritura: "todavía no he aprendido a escribir para el silencio”, dice Caparrós en Una luna (2009: 62). El viaje es excusa, método de exploración. Viajan para estar solos, para elucubrar sobre sí mismos y sobre los Otros, para escribir. Dickens decía que las ideas hay que pasearlas; Nietzsche, que como mejor se piensa es caminando, que los únicos pensamientos válidos son los pensamientos caminados. Esto es lo que hacen estos dos autores, cada uno a su manera.

La poética del movimiento se convierte en topografía transitable, en mapa. Ambos ponen en escena el ejercicio de mirar -como escribió Saint-Exupéry en Tierra de los hombres: "no hay que aprender a escribir sino a ver. La escritura es una consecuencia de la experiencia, pero sobre todo de la mirada” (cf. Sorela 2000: 11) - y someten el entorno a su observación. Son voyeurs, pero como dice Caparrós, la suerte es haber conseguido hacer de ello un oficio.

Martín Caparrós hace una suerte de arqueología del presente, de lo real, por esas ruinas tan contemporáneas en las que se adentra cuando viaja: la religiosidad, el cambio climático, los inmigrantes, el hambre o el concepto mismo de país. Sus exploraciones son ambiciosas y sus títulos lo reflejan: La voluntad, La historia, El interior. Influye en sus textos no sólo su condición de cronista sino de historiador de formación, preocupado por los datos, por las genealogías, cronologías, antecedentes, las conexiones entre los hechos. La arqueología de Chejfec es superficial, según sus propias palabras: "indicios modestos, irrelevantes y hasta azarosos, indicios menores y prescindibles, testigo de lo anónimo y lo inclasificable de la historia” (Chejfec 2008: 38). Sus soliloquios, sin llegar a ser «viajes inmóviles» tal como los definió Marc Augé (2006: 11) (en su obra se mueve, sin duda, la mente y la imaginación), son más bien pensamientos caminados (artefactos de pensamiento narrado, como los llamó Vila-Matas (2009: web), "ensayo en movimiento" -ese concepto de Fernández Porta-, novela autobiográfica en movimiento, según Jorge Carrión (2009: 53). Sus libros son experimentos narrativos, ejercicios de estilo: una literatura difusa, vacilante, abierta al ensayo y al error, a las fisuras. Casi vanguardia, Chejfec es consciente de su ser contemporáneo (Trejo 2009: 19).

La narración en movimiento de Sergio Chejfec es una especie de nouveau roman adaptado al relato de viaje: le resta importancia al personaje, a la trama y al narrador y privilegia, en cambio, la descripción minuciosa ya no sólo de la escena sino del pensamiento, confiando en la capacidad narrativa de ese recurso. También su escritura es un flujo de consciencia a lo Proust, à lo Joyce casi, a veces más lento, otras más veloz: se trata de recuerdos que le van asaltando, formulaciones a posteriori, promesas del texto que no llegan a cumplirse: "más adelante explicaré que” es una fórmula que emplea a menudo, además de los etcéteras. Y esas promesas tienen que ver con el manejo del tiempo, con una construcción del relato 
que siempre se ve postergada. Sus escenas duran varios folios y sus descripciones son kilométricas -desde la raja en la madera en la estatua de un santo hasta los contornos de un parque, sus senderos, su arenilla, su lago y la flora y fauna que lo habita-.

Pero Chejfec más que revelar el mundo, revela su mundo. Sus narraciones caminadas se convierten en libros de miradas que ponen en escena ese ejercicio de observación que es todo viaje -en su caso, paseo-, en el que lo descrito es pretexto para la disquisición, el recuerdo, el soliloquio. Un hombre deambula por un parque en una ciudad al sur de Brasil. Eso es todo lo que sucede en Mis dos mundos. Aquí no intenta el correlato de un país, aunque a veces ponga en paralelo el parque con la selva, la ciudad y el Brasil económico y urbano, algo que apenas enuncia. Mis dos mundos es más una cartografía personal de su ser en movimiento. Pero su fascinación por Rafaela Baroni, la artista popular venezolana que protagoniza Baroni, un viaje, sí se transforma en el mapa involuntario de un país a través de su iconografía, un retrato de un pueblo supersticioso y humilde, creyente, piadoso, que es devoto de la Virgen del Espejo al tiempo que acude a que le lean el futuro en su cédula de ciudadanía. Sin querer queriendo, consigue una imagen nítida y casi bucólica de los Andes, del temperamento andino -personajes que borran su presencia hasta pasar inadvertida, atentos y silenciosos, reservados, en los que influye la altura y la desolación del páramo-. Lo suyo es pura plasticidad: el olor de los mangos que satura el aire, un taller empolvado por falta de uso, el paso entre el campo y la ciudad a través de carreteras de tierra, las peleas de gallos, el silencio y la calma del altiplano, el aire empapado de rocío, la neblina, los contornos difusos de las nubes que corren a toda velocidad y de las que depende la luz, la sombra y la temperatura que pasa caprichosamente del frío al calor. Podemos ver en sus párrafos infinitos esos territorios vacíos de la zona rural, las tonalidades del verde de las montañas y la naturaleza imponente, el relieve del terreno, esa sensación de melancolía de los pueblos, el clima cálido y húmedo dependiendo de la altura, los perros que duermen echados en el letargo típico de la cordillera. Pero no sólo la imagen es paisajística: también queda dibujada la producción artística nacional (a través de Ígor Barreto o del pintor Armando Reverón), la espiritualidad y las necesidades religiosas del país y de ese ser casi mágico-realista que también es el venezolano. Incluso retrata la importancia de Simón Bolívar, esa figura que pertenece tanto a la devoción patriótica como a la religiosidad popular. "Baroni fue la gran excusa para escribir sobre Venezuela”, dijo el autor en una entrevista en El Universal de Caracas (Méndez 2007: web).

Chejfec es, sobre todo, un hombre que mira. Narrador sofisticado, en su literatura las descripciones son contornos teatrales, casi comentarios escénicos, retazos de una historia, un lugar, un contexto, una locación. Son pensamientos caminados, ejercicios de puesta en escena. Las caminatas por un jardín, por un parque brasileño o un pueblo de la cordillera hacen que lo que sucede al margen del pensamiento sea del todo ornamental y utilitario. Él mira con distancia. Lo suyo es una relación poética con el entorno, con la realidad física y el espacio, de ahí que "busque siempre la perspectiva, el mirador, la plataforma que le permite el alzamiento de la mirada” (Carrión 2012: 7). El calor intenso influye en su escritura de la escena, contagia los contornos difusos, las refracciones de la luz que distorsionan, el tiempo que se ralentiza. El viajero se integra sólo 
momentáneamente a la dinámica de los lugares. El suyo es el testimonio de un paso, es la puesta en escena de su desplazamiento. El viaje sucede en su cabeza: "el entorno, presente e invisible a la vez cuando se transforma en ambiente" (Chejfec 2007: 55). Sus viajes son a través de infinitos puntos digresivos, por una región, sí, pero sobre todo por su cabeza. Chejfec, como dice Ernesto Calabuig (2013: 16), "no busca lugares, sino signos a lo lejos". Sus temas son cuestiones tan vaporosas como la levedad, la mirada, los objetos, el pasado, el arte, la espera. Y su demora digresiva, las largas disquisiciones también tienen que ver con una especie de sensualidad del lenguaje, la seducción de las palabras como si fueran una fuente por la que fluyen las palabras y, como el agua, no se pueden atrapar, corren, se escapan. De ahí que la topografía de sus libros sea muy difícil de cartografiar, porque las referencias son apenas indicios: un parque como una marcha verde en medio de una ciudad al sur de Brasil, un pueblo en la cordillera con río y camino de tierra. La suya es una nomenclatura casi tan difusa como la que se da en muchos países suramericanos, esa que se apoya en auxilios referenciales: un árbol, una piedra pintada, un restaurante, una casa blanca... Quizá porque como el mismo autor de Mis dos mundos sugiere, la realidad no es abarcable, el mapa, inútil. De ahí que lo suyo sea la escenificación de un correlato: el de su pensamiento, y todo lo que describe hace las veces de referencias en esa cartografía o maqueta por la que discurre un texto indeterminado -no se sabe bien si ensayo, novela, biografía, paseo, flujo de pensamiento-, donde incluso las personas son descritas casi como objetos:

Se trata de un "hombre sin historia", solitario, monológico como la novela, porque la novela es él, el resto es una simple decoración que limita las acciones y congela la relación de quien cuenta con el resto de lo que se ve o acontece. El personaje -o el narrador- se cosifica y se hace correlato metafísico, un signo que teoriza (Hernández 2010: web).

La puesta en escena en Martín Caparrós es muy distinta. La poética del viaje y el movimiento de ambos autores poco tiene que ver en la ejecución, los propósitos, las consecuencias. Si en Chejfec los lugares incluso carecen de nombre y podrían ser cualquiera (Chejfec 2008: 100), el desplazamiento del autor de Larga distancia es más concreto. Sus espacios hacen parte de una cartografía reconocible, que corresponde a las nomenclaturas que todos manejamos: India, Bangladesh, Níger, Sudán, Burkina Faso, Argentina, Estados Unidos, Australia... Los capítulos de sus ensayos viajados son, de hecho, cada uno un punto geográfico. En Caparrós importan los problemas: la sequía en Nigeria, las inundaciones en Rabat, la violencia y las guerras tribales en Monrovia, la falta de pescado en Filipinas. Importa la gente: Natalia, una chica de un solo ojo que pierde a su madre y que es maltratada por su familia, vendida por su marido, violada y prostituida en El Líbano, y que le sirve al escritor para retratar un país, su machismo y las formas de las relaciones. Son protagonistas los inmigrantes, los que se quedan atrapados en la bisagra de dos culturas, los que cargan con sus países y su idiosincrasia a cuestas, los que se encierran en sus tradiciones en el lugar de destino -viaje sin viaje- los que sueñan con volver a casa y extrañan su idioma y su gente, los que pasan hambre, los que son incapaces de soñar. Caparrós se obsesiona con lo poco que 
anhelamos los seres humanos: una casa, un coche, un trabajo, una mujer bella, una buena vida. Y de ahí que relacione la pobreza con reducción de la capacidad de imaginar, con esa certeza de media humanidad de que la vida es para otros. Y es a través de esas historias que Caparrós utiliza la 'técnica del ensartado', común al relato de viajes, por medio de la cual se intercalan, dentro de la narración, las historias de otros personajes que el viajero se encuentra en el camino y se entrelazan al hilo de su narración-. La sucesión de encuentros, miradas, impresiones y sobre todo abstracciones son las que permiten elaborar ese mapa del movimiento. A veces un haiku es puntuación, o el silencio, o el cambio de escena a través de personajes que aparecen y desaparecen.

En Sergio Chejfec los personajes son espectrales, casi fantasmas que entran y salen de escena: un poeta muerto, un escultor en su taller, un viejo en el banco de un parque, Baroni como una presencia casi vaporosa -personajes que van y vienen entre distintos mundos- mientras que las figuras en Caparrós son tangibles, sólidas, de carne y hueso.

Y si en Chejfec un hombre puede ser la medida de una ciudad o un país, Caparrós se vale del hombre como medida de una condición humana. Él es capaz de hacer con la soja o las vacas la síntesis de una nación. Y los lugares que relatan tienen un 'efecto mundo': un parque que es todos los parques, un hambre que es todas las hambres, un pobre que son todos.

Caparrós es además un gran contador de ciudades. Los lugares parecen infinitos hasta que su mirada comienza a cartografiarlos. Porque Caparrós ejerce esa labor de traducción que es propia a todo viajero: él pone en escena la importancia de mirar, de entrelazar las historias, producto de su condición de cronista. Pero sobre todo exprime el diálogo con los otros -lo suyo es escuchar, y su viaje es sobre todo un ejercicio de escucha. Viaja para contar sus logros, sus problemas, sus horizontes cortos, su desesperación. Así, además de traductor es un testigo, y en eso también se aleja de Chejfec: porque no es lo mismo actuar como testigo de la vida privada de un parque, de la espiritualidad de un país a través de tallas de madera, que del hambre, la miseria, el desarraigo.

Porque Chejfec dialoga sobre todo consigo mismo -pasea en silencio, habla con su propia voz en su cabeza y el fluir de su consciencia en elucubraciones dispersas. Pensativo, camina con una especie de melancolía que dice que es necesaria para habitar el mundo, así sea de forma profunda o superficial (Chejfec 2007: 112), y se asoma a historias ajenas casi por azar. Él establece un diálogo con lo que observa la arenilla del parque del sendero por el que camina, o las carpas de un lago o la mesa del café en la que se sienta- todo como punto de partida de una nueva digresión. De ahí que la realidad de sus libros pivota entre su mirada y la representación.

Chejfec mira, elucubra, especula; Caparrós pregunta y duda, se interpreta a sí mismo y al interlocutor, al propio texto, al escenario que visita. El autor de Baroni deambula por la página, por sus ideas, por el espacio mental, -por el laberinto de significados del que hablaba Bachelard en la poética del espacio- divagando entre un árbol de imágenes y reminiscencias que se ramifican para no llegar a ninguna conclusión. Uno es un viajero factual -“de relatos que piensan, ensayos que cuentan” (Carrión 2014: web)-, Chejfec es más metafísico o más bien un narrador empeñado en un ejercicio de percepción. Caparrós emplea los datos como parte de 
las estrategias narrativas del texto, estadísticas que seducen. Es la definición misma del viaje como información, como ejercicio periodístico, al tiempo que no renuncia al ensayo en movimiento, a buscar respuestas, a formular mejores preguntas. El autor de Una luna pone su atención no en los objetos sino en la gente y es más propenso a ensayar conclusiones, sentencias. Como cuando dice: "cuanto más desarrollada una sociedad, menos depende del clima"; o "mientras más lejos está una persona de la necesidad de conseguir alimento, más lejos de su animalidad”, o "Nada hace más distinto a un hombre que haber matado a otro"; o "la idea del fin del mundo nada tiene que ver con la geografía" o que los hombres no sabemos vivir sin la amenaza de un Apocalipsis o sin la idea de patria. Caparrós ensaya dividir el mundo entre países en los que, en el taxi, los pasajeros se sientan en el asiento trasero o los que se sientan al lado del conductor; países en los que se puede beber agua del grifo y los que no; países de los que se emigra y de los que no. Son verdades que va arañando a su experiencia viajera, como si el mundo fuera una fábrica al que hubiera que robarle el saber, como Prometeo (Caparrós 2010, 20). Pero al final siempre duda: "a veces en estos viajes tengo la sensación de estar a punto de entender algo. Por supuesto nunca me sucede” (Caparrós 2010: 33). De nuevo es el viaje desde la caverna. La sed del conocimiento o por lo menos de entender algo, que nunca se apaga.

\section{3. ¿Viajeros? Hiperviaje, metaviaje, interviaje}

¿Pero se puede llamar viajeros a Sergio Chejfec y a Martín Caparrós? No se trata de la falsa dicotomía de las etiquetas -sobre todo cuando hablamos de un género híbrido, mestizo como el relato de viaje-, pero la aproximación resulta pertinente.

Es verdad que no son aventureros con sed de adentrarse en lo desconocido. No hay en sus obras retazos de Melville o Conrad; no persiguen ninguna ballena blanca ni buscan a Malrow en el corazón de las tinieblas -aunque en Caparrós sí que hay asomo al corazón de las tinieblas contemporáneas: el hambre, las migraciones, el cambio climático que los gurús de la corrección política pintan como el Apocalipsis-. Ellos no tienen enemigo al que derrotar como los héroes viajeros de aventuras. La búsqueda es personal, interior. No hay urgencia del viaje, como sí introspección y soledad. Sus relatos no son relatos del viaje al uso, que ponen por escrito la experiencia viajera o dan testimonio de su paso por un lugar o un periplo. No son Bill Bryson en las antípodas, Flaubert en Oriente, Alexandra David-Néel entrando en Lasha o Patrick Leigh Fermor de Holanda a Estambul, cruzando el continente europeo. Pero aunque ambos descreen de las etiquetas, sí hay presencias e intertextos que definen su escritura.

Sergio Chejfec es un paseante solitario que deambula como un extraviado y sin destino particular. Camina indeciso, invisible. Por eso es común verle asociado con el ensayo en movimiento de Sebald, Robert Walser, Peter Handke o incluso el flâneur baudelairiano y de Walter Benjamin. Pero lo cierto es que no hay tradición ni intertexto para sus paseos descreídos. De hecho dice no haber leído La tarde de un escritor, de Handke, un libro con el que se suele comparar Mis dos mundos. También la asociación con Sebald le resulta incómoda: 
Creo que Sebald es un escritor genial, y yo simplemente hago lo que puedo; si bien tengo ciertos reparos respecto a uno de sus libros: Austerlitz, sobre el que escribí una cosa. No me molesta que me comparen, insisto, pero me parece una incongruencia. Con su obra, Sebald pretende transmitir algo muy concreto, algo relacionado con la historia y la cultura europeas. Por otra parte, hay en él un sentido de culpa que pone de manifiesto en sus libros. Lo que yo pretendo transmitir es algo más difuso, no tengo una intención tan definida como la que tenía Sebald (Trejo ibíd: 16).

Chejfec, además, desconfía de la caminata, dice andar indolente ante lo que lo rodea, movido casi por una que se traduce en inercia, incapaz, como él dice de sí mismo, de una emoción neta y directa. Camina por una especie de nostalgia vacía, sin objeto, aturdido por el entorno, y se olvida del motivo de hacerlo (Chejfec, 2008: 55). En él el deseo de aventura cede paso al desgano, se declara incapaz de ver lo nuevo y solo de distinguir lo repetido. No busca -ni encuentra- ninguna revelación:

No como los caminantes de antes que recibían revelaciones o creían describir aspectos del mundo o relaciones con la naturaleza hasta entonces ocultas [...] No ha sido en mi caso como en el pasado, cuando los caminantes sentían reencontrarse con algo que sólo se ponía de manifiesto en el trance de andar [...] yo nunca encontré nada, sólo una vaga idea de lo novedoso o lo diferente, por otra parte bastante pasajera (Chejfec 2008: 54-55).

\section{Chejfec no se reconoce en la figura del flâneur:}

No se puede ser flanéur. El narrador comprende que lo que le ha servido, lo que ha querido hacer durante toda su vida: pasear, caminar, conocer, ahora ya no le aporta nada. Es como si se hubiese desvanecido su curiosidad. Hay nostalgia por lo perdido y ansiedad por intentar recuperarlo. Y hay tensión porque se palpa que lo que se anhela es irrecuperable (Trejo ibíd.: 17).

Así Chejfec se desmarca también de la tradición de caminantes como Stevenson o Hazlitt, de Thoreau, Rilke, de Las notas de andar y ver de Ortega o de la euforia del caminar de Vila-Matas, todos autores que ejercían o ejercen esa acción sencilla de andar a pie movidos por el placer descubridor o simplemente el acto gozoso de la caminada. Para Chejfec vagar es parte de la experiencia narrativa. La caminata es un hilo que conduce el relato. Por eso es difícil hablar de influencias en alguien que incluso describe su escritura como un ejercicio inútil y bastante banal (Chejfec 2008: 118), que llega incluso a decir que no tiene nada que transmitir (Trejo ibíd.: 16). Por eso su voz es radical, aguda, erudita, tremendamente única.

Martín Caparrós, por su parte, desconfía de la idea del viajero, le parece reduccionista: "los problemas son los que me interesan. Si yo viajo a Sri Lanka a investigar sobre la pedofilia, lo que importa no es que yo haya viajado. La literatura de viajes consiste en que alguien cuenta cómo pasó por ahí. No me gustaría asimilarme a eso. Quiero acercarme a los problemas, no escenificar desplazamientos”, dijo en la presentación de El interior en Barcelona. Y no sólo no 
se ve a sí mismo como un viajero sino que de algún modo añora esa vieja época en que "desplazarse suponía cierto esfuerzo", en la que "los viajes eran eso que un sujeto preparaba durante cierto tiempo y que lo llevaban a un lugar radicalmente otro, donde las costumbres era diferentes, donde era muy difícil comunicarse con su casa, donde tenía que intercambiar con los locales. Ahora es muy difícil salir del hiperviaje: nos desplazamos por el mundo como quien cliclea links: limpito" (Caparrós 2009: 59).

Pero a riesgo de contradecir al autor, hay que decir que Caparrós se comporta como un viajero al uso. Aunque no quiera verse de ese modo, es un ser entrenado en recorrer y contar el mundo. Larga distancia y El interior son puestas en escena, por escrito, del desplazamiento realizado: una vuelta al mundo -al exterior-, una vuelta a la patria -el interior-. También Una luna o Contra el cambio son ensayos viajados donde el escritor actúa como viajero en su actitud testimonial, en su conciencia de ser testigo de una época y una problemática, aunque dude y se pregunte si merece la pena. Es la puesta en escena de la vida de los otros pero también de su viaje, de sus movimientos. Como Herodoto. Caparrós viaja con más medios pero casi con las mismas preguntas del griego que escribió su Historia cinco siglos antes de Cristo.

Herodoto empieza su libro con una frase en la que explica por qué y para qué lo había escrito: "Herodoto de Halicarnaso va a presentar aquí frutos de sus investigaciones llevadas a cabo para impedir que el tiempo borre la memoria de la historia de la humanidad" [...] Es consciente de que la memoria es defectuosa, frágil, efímera e, incluso, ilusoria. De que todo lo que guarda en su interior puede esfumarse, desaparecer sin dejar rastro. [...] En el mundo de Herodoto, el individuo es prácticamente el único depositario de la memoria. De manera que para llegar a aquello que ha sido recordado hay que llegar a él; y si vive lejos de nuestra morada, tenemos que ir a buscarlo, emprender el viaje, y cuando ya lo encontremos, sentarnos junto a él y escuchar lo que nos quiera decir, escuchar, recordar y tal vez apuntar. Así es como, a partir de una situación como ésta, nace el reportaje. Herodoto viaja por el mundo, encuentra a otros hombres y escucha lo que cuentan. Le dicen quiénes son, le cuentan sus vidas (Kapuscinski 2006: 90-91)

Martín Caparrós es un viajero en la línea de Herodoto, de Tucídides, cuyos métodos son especulativos y se mueven para comprender las causas de las guerras entre los hombres (y qué guerras más contemporáneas que la inmigración o el cambio climático que aborda Caparrós en Una luna o Contra el cambio). Comparte la misma tradición de autores como Lévi-Strauss (la de Caparrós es una antropología del presente), John Dos Passos, o escritores como Robert Kaplan -con su ensayo sobre el Océano índico, por ejemplo--, Ryszard Kapuściński, Octavio Paz y sus Vislumbres de la India, Cortázar y sus Autonautas de la cosmopista o la obra de autores como Jan Morris, Philip Hoare -ensayistas experimentales-, o Jon Lee Anderson con sus libros sobre Bagdad, las guerrillas o las zonas de guerra. Como todos ellos, es un humanista:

La diferencia entre un turista y un viajero es que el turista no sabe de dónde 
viene y el viajero no sabe adónde va. Estaba bien dicho, pero hoy se me ocurre que la diferencia también tiene que ver con otras cosas. Al turista le ofrecen un menú con dos opciones: visitar restos del pasado humano —ruinas, museos, monumentos varios - o escenarios actuales de la naturaleza — vistas, playas, paisajes-; me gustaría creer que los viajeros quieren saber qué hacen, aquí y ahora, los hombres. El viajero, caramba, sería un humanista (Caparrós 211: 62).

Ambos autores viven la descoloración, el desplazamiento y extravío que requiere el viaje. Ejercen esas dos actividades diferentes pero correlativas que son leer y caminar el mundo y el paisaje. Ese acto narrativo que es el viaje del que han hablado tantos autores, entre ellos Michel Butor -"la escritura como viaje y el viaje como escritura” (Butor ibíd: 17-19)- o Alberto Manguel:

Viajar es acto narrativo. Pasar de un lugar a otro cruzando espacios que no conocemos es, en cierto modo, hacer literatura: al fin y al cabo, una de nuestras más antiguas metáforas declara que el mundo es un libro. El viajero construye historias a partir de lo que ve y escucha y siente, y atribuye a sus partidas y llegadas las características de una primera y de una última página. Las personas con las que se encuentra se convierten en personajes de su historia; a veces es el viajero el protagonista, a veces son los otros. Paso a paso, el viajero descubre y también inventa su narración. Ponerla por escrito no es sino un paso más, por cierto no el esencial (Manguel 2012: 2).

Pero si hay una etiqueta común que puede agrupar a estos dos autores es la de metaviajeros - producto de la postmodernidad y la globalización-, que en sus obras reflexionan sobre el acto mismo de viajar, leer y escribir el territorio, el tiempo y el espacio. Jorge Carrión define la figura:

El metaviajero de nuestra postmodernidad última no va, regresa (así hay que entender los libros del cambio de siglo de W.G. Sebald, Juan Goytisolo, Cees Nooteboom, Wim Wenders, Peter Handke, Claudio Magris, Edgardo Cozarinsky, Gao Xingjian, Miquel Barceló), o cuando va por primera vez, es tal la información previa acumulada, que hay en su experiencia menos conocimiento que reconocimiento (los reportajes de Martín Caparrós o de David Foster Wallace, por ejemplo). El viaje se da en paralelo al de los viajeros precedentes, como ha ocurrido siempre; pero por vez primera el marco semiótico está sobresaturado de textos y de lenguajes [...] Los filtros se problematizan. Se explicitan el testimonio, la lectura, el intérprete, la lengua franca (el inglés, por lo general) o los factores del contexto. Son obras de altísimo nivel estético e intelectual cuya naturaleza formal es mutante -alimentadas por el motor del viaje, que van encadenando aspectos y tópicos del viaje, sometidos a una mirada crítica y, al mismo tiempo, poética. En el fondo, como horizonte de todo el arte de viaje de nuestra época, se muestra de un modo u otro la dificultad añadida por la globalización (Carrión 2007: 33).

El ejercicio intertextual en Chejfec tiene que ver con Borges, con el poeta Juan Sánchez Peláez -del que copia ciertos versos en Baroni-, con el uruguayo Mario 
Levrero o con Ricardo Piglia, César Aira, Juan José Saer, Antonio Di Benedetto o incluso el propio Martín Caparrós. El autor de Larga distancia alude a otros viajeros que han pasado antes que él por los lugares que visita, como Orellana en el Amazonas o Kapuściński en su paso por África. Reconoce la influencia de $\mathrm{La}$ vuelta al mundo en 80 días y también de Domingo Faustino Sarmiento -ese escritor argentino del siglo XIX que viajó al exterior también en busca de respuestas-, Rodolfo Walsh, Manuel Vicent, Truman Capote o Tomás Eloy Matínez.

Pero son metaviajeros no tanto porque sus libros sean intertextuales al uso: no se trata sólo de ver con ojos ajenos, reconocer lo que otros han escrito para luego añadir, refutar, complementar, sino que ahora el intertexto se suma a la experiencia de otro modo. Porque los territorios de Caparrós no han sido transitados antes por muchos viajeros ni son escenarios típicos de la escritura de viajes. Aquí el intertexto funciona como parte del ensayo, pero también como formas de puntuación del relato, como bibliografía, contrapunto o voz que dialoga con el monologista principal.

Son hipermetainterviajeros: su escritura reflexiona sobre la condición del escritor y la experiencia literaria, sobre la condición del viajero y el paseante en contrapunto con el turista, además de la preocupación por el mundo contemporáneo cada vez más angosto que borra las diferencias con la homogeneización visual, las cadenas comerciales, la ropa clon, los estilos arquitectónicos transfronterizos, ciudades que quieren ser California. Ambos reflexionan sobre el mundo convertido en un parque temático, un mundo de sucedáneos, barrios que se convierten en escenarios y ciudades en decorados. "Un mundo", como dice Caparrós, "que se preocupa hasta las lágrimas por la desaparición de una oruga javanesa no se inquieta demasiado por la pérdida de esas formas de vida, esas culturas" (Caparrós 2014: web).

La poética del movimiento de ambos autores también está emparentada con la posmodernidad. Caparrós habla de hiperviaje: "rebotar de un lado a otro" saltando de país en país, de provincia en provincia. El de Chejfec también lo es, a su manera: hiperviaje del pensamiento -pensamiento hipertextual-, los suyos son saltos entre objetos, observaciones, digresiones, ensayo, recuerdos. Brincos de un encendedor y un reloj heredado de su padre que le dan pie a contar una suerte de biografía familiar a los cisnes mecánicos de un lago o un campesino que habla por la televisión como excusa para ir y venir en el tiempo, en el espacio, de un parque suramericano a otro en Europa, de su yo del presente al yo pasado y futuro. El tiempo es el que camina, más que él mismo, sentado en un banco: "mi atención toma la forma de enlaces de internet [...] son asociaciones que surgen, reminiscencias, parecidos, vínculos, evocaciones, ramificaciones del pensamiento que me desbordan y me dejan exhausto (Chejfec 2008: 25). Son los tiempos verbales los que van y vienen, el mosaico de digresión y descripción se mueve mucho más que el caminante, que puede estar sentado en un parque. Podríamos hablar incluso de una especie de movimiento en la quietud, que avanza pero no se mueve. Los saltos son entre los personajes y objetos que son observados. Su lente casi inmóvil podría ser comparada más con instantáneas que con el flujo de una cámara cinematográfica. Y sus ojos -como cuando en Mis dos mundos evoca a Kentridge- responden a esa línea punteada de miradas que podría ser a todas 
partes. Quizá sus libros deberían leerse a "la velocidad de la caminata, lo más indicado para la observación y el pensamiento -la experiencia corporal del viaje”. Quizá los libros deberían ser leídos a la velocidad que fueron escritos.

\section{Técnicas y estrategias narrativas de un género híbrido}

Ya nadie duda de que hoy los géneros son porosos, líquidos, híbridos, mestizos. Sabemos que lo puro no es más auténtico que la mezcla, como sugiere Caparrós y hay que desconfiar de la pureza. Aquí no hay libros purasangre, no hay sangre azul. La novela se cruza con el ensayo, la crónica, la bitácora de viaje, la biografía, el ensayo antropológico, la historia, el perfil, el documento científico, una reflexión sobre arte... Géneros que dialogan para tejer un mundo poético propio en los que movimiento es el eje principal del relato.

Pero asimilar a Martín Caparrós con Herodoto y Kapuściński obliga a hablar de la crónica, ese género que el autor de Contra el cambio es maestro. Pero él niega la mayor: dice que sus viajes no son crónicas, sino diarios de un hiperviaje, ensayos viajados. Tiene razón, en parte, si aceptamos su argumento de que no escenifica sus viajes en la escritura, sino que ensaya posibles respuestas y mejores preguntas frente a problemáticas contemporáneas. Los libros de Caparrós, de nuevo como los viajes del griego de la Historia y el polaco de La guerra del fútbol, son autobiografía en movimiento y bitácora de viaje, ejercicio periodístico, ensayo viajado, dietario, monólogo, collage en el que a veces la puntuación puede ser un poema. Pero eso es lo que el relato de viaje ha sido siempre, desde el griego que inventó el género y que tampoco viajó para poner en escena su viaje sino para confirmar lo que había oídos decir sobre los Otros, para evitar que ciertos hechos se perdieran de la memoria de los hombres y, sobre todo, también para responder una pregunta: el por qué de las guerras, que es el punto de partida de su Historia. Caparrós viaja hoy con más medios, pero las preguntas son muy parecidas: la afinidad técnica radica en la pregunta, la misma con la que viajó Herodoto, y en la idea de que allá, en los Otros, es donde están las respuestas.

Los viajes de Martín Caparrós se apoyan en lo factual, tienen la gran carga informativa que caracteriza los libros de viaje. Su escritura recurre a estrategias comunes a todos los viajeros: el perfil de los personajes y las historias ensartas, la entrevista, el diario, su propia reflexión al paso, la pincelada, el dietario pulido a posteriori, la libreta 'desgrabada' del caminante. No hay falsa neutralidad en su escritura. Como explica María Angulo, los suyos son:

códigos retóricos del periodismo (la actualidad, la oralidad, la fragmentación, la descripción, los datos, la importancia de la anécdota, el suceso, el hecho diferencial, la argumentación) y las estrategias discursivas de la narrativas del yo (el monólogo interior, la primera persona, la validez de lo subjetivo, la constatación de la duda, el poder de los sentidos, de la experiencia, de la vivencia, del «yo estuve allí», del narrador como sujeto que se instituye en el discurso, de la explicación psicoanalítica, de la reflexión metalingǘstica). Mirada de cronista: mezcla de viajero y de turista (Angulo 2014: 166). 
La escritura viajera de Caparrós sucede en dos capas: el primer nivel informativo, periodístico, de denuncia incluso -comprometido al modo de Voltaire o Zola, haciendo "uso del capital simbólico del artista para intervenir en la cosa pública, para pensar en público" (Carrión 2014: ibíd.)-. Pone a prueba nuestras ideas sobre el hambre, la pobreza, el cambio climático, la inmigración. Usa la entrevista, el perfil, la crónica. Es un ejercicio de escucha, de pura interpretación. Desenfadado, informal pero riguroso y políticamente incorrecto, inteligente, incómodo. Pero hay un segundo nivel que es el desplazamiento en búsqueda de sentido. El viaje interior.

La obra en movimiento de Sergio Chejfec cuesta más delimitarla dentro de las fronteras de este género híbrido que es la escritura de viajes, ya que sus desplazamientos, más que físicos, son literarios. Pero si nos atenemos a la poética del relato de viajes que formuló la investigadora argentina Sofía Carrizo (1997), que alude a los picos de clímax que impulsan la narración hacia el desenlace no es la aventura sino la descripción y el espectáculo del mundo que se presenta, con sus anécdotas y escenarios, la obra de Chejfec encaja sin condiciones. Aunque está lejos de lo factual o periodístico, su técnica se apoya en la écfrasis (en Baroni, un viaje es la más utilizada de la narración), la descripción detallada, la digresión, el soliloquio, la acumulación. Su trayectoria no es sólo viaje sino también biografía, ficción, ensayo. Y si en Caparrós el viaje y el tiempo es lineal, en Chejfec es aleatorio, desordenado: en su caso se trata de un virtuosismo en el manejo del tiempo zigzagueante, que va y viene. Los saltos temporales ocurren sin aviso, sin transición, en las que los tiempos y espacios se superponen, se cruzan. Porque como Chejfec explica, "Las cosas no ocurren de una vez y para siempre, sino que siguen ocurriendo" (Trejo ibíd.: 16).

Los de Sergio Chejfec son artefactos de pensamiento narrado y por eso en su obra hay poca acción: el peso está en las ideas que caminan, no en tramas o personajes: las que discurren las ideas, las descripciones y los conceptos y el lector es quien tiene que adaptarse a una cadencia lenta, dilatada, vaporosa, donde la narración es siempre postergada o se desvanece, es imprevisible. Son libros en los que la sensación es casi de soñolencia, de duermevela -una de las primeras editoras que leyó una obra suya le dijo que sólo podía leer una página al día-. Chejfec es testigo de sí mismo, de ahí que reconstruya su pensamiento en trance o en tránsito, mientras que Caparrós es testigo de una época, una problemática, de las vidas de otros y sus historias -como siempre los viajeros-. Ambos son incapaces de contar sin incluirse y desaparecer. Pero al autor de Contra el cambio la que le salva de poner el ojo exclusivamente en sí mismo es ese ejercicio que es la escucha que despliega en sus viajes.

Sin embargo, en ambos el yo, la primera persona, es el garante de la narración. Ellos son el personaje, el eje: es su voz y su mirada. El autor es la medida del relato. El yo es el punto que organiza la entropía, la medida que ordena el sistema que gravita en torno a ellos. De hecho es más que una primera persona: la mirada de Chejfec es como la de un hacedor que reordena el mundo a través de su mirada, lo recoloca. Y mientras Caparrós busca interpretar la realidad, Chéjfec se mira sobre todo a sí mismo, más que afuera. Antropología de lo real en Caparrós y del pensamiento en el autor de Baroni. Chejfec no cambia de punto de vista. Caparrós intercala historias que amplían la mirada. 
Uno de los componentes tradicionales en la escritura de viaje es el apoyo en fotografías, dibujos, mapas. Tanto Martín Caparrós como Sergio Chejfec aluden a fotografías, pero pocas veces las publican (salvo Caparrós en la portada de Una luna o en Pali Pali, su libro sobre Corea del Sur). En un mundo en el que las imágenes están al alcance de todos, ellos parecen no querer participar en el juego referencial, sino jugar la partida de la interpretación. En el caso de Chejfec tal vez se desmarca de Sebald, ese autor que sí que recurrió ampliamente a este recurso, quizá porque el suyo es más bien un friso, una pintura del pensamiento, "un proyecto descriptivo, una excursión semántica” como dice en su blog-. Y no se puede ilustrar lo que no se quiere mostrar. Su objetivo no es referencial. Se trata de un ejercicio de observación, de dar sentido a los otros a través de la mirada.

\section{La duda: la impotencia comunicativa}

Hay una estrategia narrativa que merece la pena destacar, no sólo porque la empleen ambos autores sino porque tiene que ver con la crisis de los mecanismos de representación de la posmodernidad: parece que el mundo ya no puede ser representado, ya no se puede narrar. La literatura compite con otros medios y medios aparentemente más eficaces y de ahí que los autores exploren artefactos narrativos nuevos.

La literatura ha incorporado a sus formas la decepción hacia sus mecanismos de representación, como el resto de las artes. Se ha contaminado de su propia disolución, porque la literatura compite con otro tipo de textos y de tecnologías que han reducido notablemente su espacio. El mundo ya no se puede narrar. Al propiciar esa confusión entre ficción y realidad, lo que hace la literatura es convertir la pérdida de su objeto en un nuevo objeto (Bujalance 2010: web).

Pero esto no es tan nuevo como parece. Es lo que se puede denominar Impotencia comunicativa, fórmula común a todos los viajeros y que tiene que ver con la confesión de que las palabras son insuficientes para expresar el mundo (todavía no he encontrado un viajero que no se manifieste inferior frente al paisaje, la sociedad, la cultura o problemática que tiene delante)-. Chejfec, por ejemplo, aunque usa y a veces abusa de la descripción, en más de una ocasión desconfía de ella, como cuando dice: "cualquier descripción de los hechos sería entendible a medias y en gran parte del todo indescifrable" (2007: 27); "No me resulta fácil describir la extraña combinación de silencio que habita en este pueblo" (ibíd.: 61); "No tengo mejor modo de describirla (una escultura) que diciendo que parece bucólica o pastoril” (ibíd.: 4). Su fe en la descripción, en la écfrasis que despliega en Baroni, un viaje, es sólo a medias:

Cuanto más preciso uno quiere ser, más detallista y escrupuloso con los matices y contrastes; cuanto más espera que el aluvión de sensaciones resulte inspirador de manera de alcanzar la fidelidad honesta con la naturaleza que se presenta con toda su exacerbación; cuanto más uno quiere ser mero instrumento, buscando el despliegue verbal propicio y la transmisión ajustada del acontecer; cuanto más 
todo eso, el resultado termina siendo más incompleto y, sobre todo, más desintegrador. Por lo tanto no me hago ilusiones (Chejfec ibíd.: 100).

Martín Caparrós también es un descreído de la descripción. Sus viajes suceden en lo que describe pero también al lado de lo que parece que acontece, en las elipsis, en lo que no dice. Su reflexión es paralela, lo que ocurre pasa "detrás de los ojos", como dice Pedro Sorela, ese otro gran viajero: "el viaje es lo que sucede detrás de los ojos, no delante y, al igual que la literatura, hace posible que de nuestro mundo hagamos una creación” (Sorela 2006: 201).

De hecho, Caparrós también echa mano de la impotencia comunicativa, por ejemplo en sus relatos en África, donde se cuida mucho al emplear las palabras de siempre: miseria, explotación, hambre, injusticia: "palabras tan gastadas que ya se esterilizaron” (Caparrós 2010: 50). O en la descripción de una escena en el barrio chino de Manila, en el que cree que un muchacho tiene la mirada de quien ha matado, pero no puede confirmarlo, y entonces le asalta "la desesperación de no saber contar lo que importa”- (Caparrós 2010: 140).

Para cierta belleza no hay palabras, el silencio suele ser el mejor homenaje: hay un punto en el que las palabras solo pueden rebajar lo que describen, porque cuando las palabras quieren describir sólo rebajan, porque cuando las palabras no se creen que son capaces de su propia belleza sino que tienen que subordinarse a una belleza externa, rebajan, se rebajan, digo: nos rebajan (Caparrós ibíd.: 190).

El mundo es renuente a dejarse describir. Por eso tanto Chejfec como Caparrós son conscientes de la distancia que existe entre el mundo que caminan, el que perciben, el que se imaginan y el que terminan por traducir en su escritura. Saben que su percepción es fragmentaria y de ahí que su escritura también lo sea: a veces se trata sólo de una frase, un poema, un verso o el flujo de conciencia. Miran, formulan, pero siempre dudan: Chejfec puntúa muchas frases con un "no lo sé"; "no recuerdo del todo bien"; "no estoy en condiciones de asegurarlo" y descree del viajero, ese que "se siente conocedor tras un paso minúsculo" (Chejfec 2007: 63), "de ese extranjero que por lo general sólo observa la superficie” (Chejfec ibíd.: 87). El autor de Mis dos mundos materializa la imposibilidad del conocimiento:

El viaje como desencanto de cualquier aprendizaje probable, o en todo caso como neutralidad, como significado casi cero. Es digamos, una serie de viajes que no sirven para nada, fuera del hecho de formar parte de este relato. Si tuviera que ser esquemático, diría que la novela tiene una matriz escénica, el viaje, y tres personajes dramáticos principales (Chejfec 2007: web).

Caparrós lo dice tajante: "el viajero no sabe una mierda: supone, busca, piensa" (Caparrós 2009: 162); “el cronista, flâneur frívolo, debe caminar cada vez más para encontrar las diferencias” (ibíd.: 160). Y termina por detestar su visión incompleta, desesperado por la pobreza de las apariencias.

Pero la conciencia de lo fragmentario nos regala una visión del mundo única y más compleja que la de aquellos viajeros que se mueven a través de certezas. Saber que su percepción es limitada nos da un mapa de indicios, sospechas, 
incertidumbres, que terminan por revelar también alguna verdad, aunque nos dejan con más dudas que respuestas. Viajan para ver, no para reconocer. De ahí que la poética del viaje en Caparrós gire sobre todo en torno a las preguntas. Como dijo Jorge Carrión en la presentación de El interior, la clave está en eso que no dice, es su estilo basado en los interrogantes, esos signos de interrogación que enmarcan el viaje: las preguntas son las que hacen avanzar la lectura.

Caminantes contemporáneos, curiosos pero al mismo tiempo incrédulos, expertos en ese ejercicio de observación que es todo viaje, Chejfec y Caparrós son escritores que de tanto caminar llegan a preguntarse por la superficialidad que supone, en últimas, el viaje contemporáneo. Defraudados por anticipado, su capacidad de sorpresa se ha reducido y la realidad ya no es capaz de impresionarlos: "Lo que sí me sorprende -dice Caparrós- es mi vida: jueves de marzo, noche de lluvia, cielo fucsia, un suburbio alejado, un vestuario de clubcito pobre, argelino senegalés maliano. Y yo, que los escucho. Yo, que simulo que lo que dicen me interesa, aunque ya sé que no me sirve para nada” (Caparrós 2008: 98-99).

Una de sus principales estrategias narrativas es, pues, la duda -mismo método que comparte con Herodoto y Kapuściński, entre tantos otros-. En Caparrós su mecanismo textual es poner el foco lejos de lo habitual, dudar de las ideas recibidas, fosilizadas, los temas mainstream, las causas que millones no cuestionan y que los poderosos hacen creer al resto como propias y que se convierten en trampa. Es lo que María Angulo define como realismo intransigente:

El cronista siempre está en guerra, siempre a la contra, inquieto con lo que ve, con lo que reflexiona, con lo que le viene del exterior y con lo que surge de su interior. Hay una intransigencia, un inconformismo innatos [...] el poder de la palabra para modificar las cosas, para denunciar e incluso para concienciar [...] Caparrós se sirve sobre todo de la ironía, con toques puntuales de autoparodia, situaciones tangibles, problemas concretos de la condición humana, circunstancias vividas, espacios visitados (Angulo ibíd.: 148-149).

Por eso su actitud ante el desplazamiento, su búsqueda, ya no tiene que ver con las respuestas como de formular mejor las preguntas. Caparrós sobre todo: Si se trata de migrantes, no intenta tanto saber por qué se desplazan, sino reflexionar sobre la limitada capacidad de soñar de los seres humanos, la atrofia de la mayoría de imaginar otros mundos posibles. Si se trata del cambio climático, la cuestión no es si debemos adscribirnos a esa religión bienpensante del ecologismo progre sino si ese es el problema ralamente prioritario en el que miles mueren al día de hambre y sed. Se trata de volver a preguntarlo todo, porque como ha dicho tantas veces Caparrós, "escribir con certezas es como bailar con la hermana".

Entre esas preguntas mejor formuladas también aparecen conceptos como guerra, hambre, miseria, desarraigo. Palabras gastadas de tan usadas y manoseadas que ya no necesitan respuestas sino preguntas. Esas son los interrogantes al exterior. Luego están las del propio viajero: su obsesión por el tiempo, que pasa, líquido, incontenible; su propia búsqueda de sentido o la aproximación ante grandes temas como la patria, el hambre, la guerra, el pasado personal, el origen, la argentinidad. Chejfec también se preocupa por el tiempo, por un deambular que de 
algún modo también busca un lugar en el mundo, que se relaciona con su origen judío de antepasados errantes a la vez que duda de la pertenencia a una comunidad cultural, étnica o nacional.

Entre esas preguntas mejor formuladas está también la de la propia identidad. "Cuando uno se desplaza a algún sitio, no hace más que viajar en pos de su propia naturaleza incomprendida”, le dijo Kafka a su amigo Gustav Janouch. En Mis dos mundos Sergio Chejfec alude a su naturaleza judía, trashumante. Caparrós ha explorado la Argentina en El interior y en Argentinismos. Quizá la condición misma del viajero es la extranjeridad, de ahí que podamos agruparlos en torno a una escritura posnacional, deslocalizada. Ambos son extranjeros que llaman casa a varios lugares. Para Caparrós -que ha vivido en Madrid, París, Nueva York y Barcelona- su patria está frente a la pantalla de su ordenador y los países los considera inventos poco interesantes y ciertamente efímeros. Chejfec -que ha vivido en Venezuela quince años y otros tantos en Nueva York- en sus libros alude a su origen y elabora sobre la dificultad de encontrar un lugar en el mundo. Ambos escenifican el desarraigo de un modo muy suyo. No se resisten a la idea de hogar, no tiene tal consuelo como una patria. Ambos son viajeros contra-espaciales, que diría Jorge Carrión, que se desplazan cuestionando su identidad nacional, sus hábitos, cultura y noción de espacio heredados, la tradición histórica de su país, reformulando su origen (2009: 28). Viajeros, en términos de Paul Bowles, que cuestionan la civilización a la que pertenecen, la comparan con otras y rechazan aquellos aspectos que no le gustan (1998: 19).

Pero al final siempre está la duda, sea cual sea la pregunta que se formulen. Estos libros abiertos, llenos de nexos, conexiones, ensayos más que conclusiones, sin sentencias ni moralejas, de cierres abiertos y más bien con puertas giratorias de entrada y de salida, nos dejan más preguntas que certezas, entre otras cosas porque están escritos por autores que saben que "comprender ciertas cosas es comprender que uno no entiende nada" o mejor, "entender es darse cuenta del desastre que somos”. Están ahí no para resolver interrogantes sino incluso para dejar al lector con nuevas dudas, porque como dice Chejfec: "la literatura no está para hacer las cosas más sencillas sino para añadir complejidad” (Trejo ibíd.: 15).

Sí, hablamos del viaje -interior y exterior- como pregunta, como mecanismo abierto en el que necesariamente el lector participa y que no revela una verdad sino varias. Porque está claro que en esta época de crisis de la representación ya no vale el relato espejo, ese que calca la realidad. Es el momento de la interpretación. Y esto es lo que reúne, al final, a estos dos autores tan diversos: el viaje como mecanismo de interrogación, nunca como certeza, donde la explicación no es académica sino experimental, a la vez que los autores se buscan y se explican también a sí mismos. Porque el viaje siempre recomienza, vuelve a empezar. Por eso las puertas han de quedar abiertas. Es el único modo de que el viaje no termine nunca.

\section{Referencias bibliográficas}

Angulo, María, “Matar una mariposa. El realismo intransigente”, en Crónica y mirada. Aproximaciones al periodismo narrativo. Madrid: Libros del K.O., 2004, pp. 143 y ss. Augé, Marc, "El viaje inmóvil”, en Manuel Lucena y Juan Pimentel (eds.). Diez estudios 
sobre literatura de viajes. Madrid: Consejo Superior de Investigaciones Científicas, 2006, pp. 9-15.

Baudelaire, Charles. Las flores del mal. Madrid: Edimat Libros, 2007.

Bowles, Paul. Bajo el cielo protector. New Jersey: Ecco Press, 1998.

Bujalance, Pablo, "La literatura se ha infectado de su propia disolución: el mundo ya no se puede narrar”, Málaga hoy, 2010. Disponible en:

http://www.malagahoy.es/article/ocio/711846/la/literatura/se/ha/infectado/su/propia/dis olucion/mundo/ya/no/se/puede/narrar.html\#sSf3LdtiGiWvuCE7

Butor, Michel, "Le voyage et l'écriture”, Romantisme. Voyager doit être un travail sérieux, vol. 2, n . 4 (1972), pp. 4-18.

Calabuig, Ernesto, “La experiencia dramática”, El cultural, 12 de abril, 2013, p. 16.

Calvino, Ítalo. Seis propuestas para el próximo milenio. Madrid: Ediciones Siruela, 2007.

Caparrós, Martín. El interior. Buenos Aires: Planeta, 2011.

—“A gentrificar, a gentrificar”, El país, 28 de abril, 2014. Disponible en: http://elpais.com/elpais/2014/04/23/eps/1398283121_375738.html

-Contra el cambio. Un hiperviaje al Apocalipsis climático. Barcelona: Anagrama, 2010.

-Una luna. Barcelona: Anagrama, 2009.

Carrión, Jorge, "Nadie puede estar cerca de Borges. Sarmiento, en cambio, sí era humano”, Jotdown, 16 febrero de 2014. Disponible en:

http://www.jotdown.es/2014/02/martin-caparros-nadie-puede-estar-cerca-de-borgessarmiento-en-cambio-si-era-humano/

— “Entre Sebald y Google. La deriva en Sergio Chejfec”, en Dianna C. Niebylski (comp., ed. e intr.). Trayectorias de una escritura. Ensayos críticos. Pittsburgh, PA: Instituto Internacional de Literatura Iberoamericana, 2012.

—Viaje contra espacio. Juan Goytisolo y W. G. Sebald. Madrid: Suramericana, 2009.

— “Del viaje: penúltimas tendencias”, Quimera, Jorge Carrión (coord.), Metaviajeros, 284/5 (2007), pp. 32-33.

— “¿Una tradición silenciada? Hacia un corpus de la literatura nómada”, Revista Lateral, $n^{0} .123$ (2005), pp. 53-57.

Carrizo, Sofía M. Poética del relato de viaje. Erfurt: Kassel-Edition Reichenberger, 1997.

Castro, Rodrigo, "Filósofos y Viajeros. El Pensamiento como Extravío” Astrolabio, Revista internacional de filosofía, $\mathrm{n}^{\circ}$. 6. (2008), pp, 1-12.

Chejfec Sergio. Baroni, un viaje. Buenos Aires: Alfaguara, 2007.

— "Sobre baroni, un viaje”, 2007. Disponible en: http://parabolaanterior.wordpress.com/2007/10/16/sobre-baroni-un-viaje/

- Mis dos mundos. Buenos Aires: Alfaguara, 2008.

Hernández, Alberto, "Sergio Chejfec, mis dos mundos", Letralia, 27 enero de 2010. Disponible en: http://www.letralia.com/ciudad/hernandez/100127.htm.

Kapuściński, Ryszard. Viajes con Herodoto. Barcelona: Anagrama, 2006.

Manguel, Alberto, “La noche europea”, El País. Babelia, 26 de mayo, 2012, p. 2.

Méndez, María Graciela, “Miradas al libro cerrado”, El Universal (Caracas), 16 de septiembre de 2007. Disponible en:

http://www.eluniversal.com/2007/09/16/imp_qhay_art_miradas-al-libro-cer_470119.

Montaigne, Michel de. Ensayos. Según la edición de 1595 de Marie de Gournay. Barcelona: Acantilado, 2007.

Nietzsche, Friedrich. Más allá del bien y el mal. Madrid: Alianza Editorial, 2003

Paredes, Juan, "De curiosidad y de lástima dejamos nuestro Derecho viaje: el viaje como marco, tema y estructura en los cuentos del Quijote”, en F. Carmona Fernández y García Cano (eds.). Libros de viaje y viajeros en la literatura y la historia. Universidad de Murcia, Servicio de Publicaciones, pp. 275-284.

Rilke, Rainer Maria. Cartas a un joven poeta. Madrid: Ediciones Hiperión, 2007.

Sorela, Pedro. Cuentos invisibles. Madrid: Alfaguara, 2003. 
— “Un escritor sin red” (pról.), en Antoine de Saint-Exupéry. Tierra de los hombres. Madrid: Círculo de Lectores, 2000.

Trejo, Juan, “Entrevista a Sergio Chejfec”, Quimera, no 302 (2009), pp. 12-18.

Vila Matas, Enrique, “Un camino insólito”, El País, 7 de junio de 2009. Disponible en: http://elpais.com/diario/2009/06/07/catalunya/1244336845_850215.html. 